\title{
EDITORIAL
}

\section{Ablation of Atrial Fibrillation Using an Irrigated-Tip Catheter: Open or Closed?}

\author{
RAKESH LATCHAMSETTY, M.D. and HAKAN ORAL, M.D. \\ From the Division of Cardiovascular Medicine, University of Michigan, Ann Arbor, Michigan
}

Since the advent of radiofrequency (RF) catheter ablation of cardiac arrhythmias, innovations in catheter design and technology have provided the operator with a growing selection of ablation catheters. In contrast to ablation of common supraventricular arrhythmias, where ablation of a well-defined single site results in excellent clinical outcomes, ablation of complex arrhythmias such as atrial fibrillation (AF), atrial flutter, and ventricular tachycardia often requires multiple and larger lesion sets. Because recovery of conduction plays a key role in recurrence of these arrhythmias, it also is important to create transmural lesions that are likely to be permanent.

In this issue of the Journal, Golden et al., ${ }^{1}$ report clinical outcomes using a closed-irrigatedtip catheter for ablation of AF. RF catheter ablation was performed in 195 patients with paroxysmal $(56 \%)$ or persistent AF (44\%) with a closed-irrigated-tip catheter that had a 3.5-mm tip electrode (Chilli II, Boston Scientific, Natick, MA, USA). RF energy was delivered in a temperature-controlled mode with a target temperature of $40^{\circ} \mathrm{C}$ at a maximum power of 35-40 W (25 $\mathrm{W}$ along the posterior wall). First, pulmonary vein isolation was performed during AF, followed by a stepwise approach of linear ablation, ablation of complex fractionated electrograms, coronary sinus isolation, and superior vena cava isolation until AF terminated and was not inducible, or the steps were completed with a substantial decrease in AF cycle length.

After a 6-week blanking period, recurrence of $\mathrm{AF}$ was defined as any symptomatic episode longer than 5 minutes in duration or any documented episode of AF on an electrocardiogram, Holter monitor, or device interrogation for $>30$ seconds. Patients with a recurrence were offered repeat ablation or antiarrhythmic drug therapy. Follow-up visits were performed at 6, 12, 24, and 36 weeks and at the physician's discretion

\footnotetext{
Address for reprints: Hakan Oral, M.D., Division of Cardiovascular Medicine, University of Michigan, CVC, SPC 5853, 1500 East Medical Center Dr., Ann Arbor, MI 48109-5853. Fax: 734936-7026; e-mail: oralh@umich.edu
}

Received Dcember 21, 2011; accepted January 05, 2012.

doi: 10.1111/j.1540-8159.2012.03333.x thereafter. An event monitor was provided for 1 week in one-third of the patients.

A repeat ablation was performed in $9 \%$ of the patients. The mean duration of RF energy application was 75 minutes and $76 \%$ of the patients converted to sinus rhythm during ablation. At a median follow-up of 56 weeks, $74 \%$ of the patients were free from $\mathrm{AF}$ after a single ablation procedure and $77 \%$ were free from $\mathrm{AF}$ after a second ablation. However, $56 \%$ of the patients were still on antiarrhythmic drug therapy. Major complications were observed in $7 \%$ of the patients, including cardiac tamponade in four and cerebrovascular events in two patients.

The authors are to be commended for a detailed report on clinical outcomes of catheter ablation of AF using a closed-irrigated-tip catheter in a large number of patients. The major limitations of the study are lack of a comparison group, concomitant antiarrhythmic drug therapy in a large proportion of patients who remained in sinus rhythm after catheter ablation, and absence of long-term electrocardiographic assessment of outcome in the majority of the patients. Nevertheless, as reported, the complication and success rates appear to be comparable to prior studies, ${ }^{2}$ although a higher number of patients in this study did remain on antiarrhythmic drugs.

At present, there are four major types of RF catheter ablation systems available for clinical use in the United States: (1) standard 4-mmtip catheters; (2) large 8-10-mm-tip catheters; (3) open-loop irrigated-tip catheters; and (4) closedloop irrigated-tip catheters (Table I). Although power delivery is often limited by high temperatures at the electrode-tissue interface in nonirrigated systems, active tip-electrode cooling in open-loop irrigated-tip catheters enables increased power delivery without an increase in the risk of thrombus and char formation. ${ }^{3,4}$ Therefore, larger and transmural lesions can be created with an improvement in ablation efficiency and efficacy. ${ }^{5}$

Studies that compared open-loop irrigatedtip catheters to standard 4-mm-tip catheters have demonstrated an improvement in the maintenance of sinus rhythm with a similar complication rate after catheter ablation of AF with an openloop irrigated-tip catheter. ${ }^{5,6}$ Although large-tip

(C)2012, The Authors. Journal compilation (C)2012 Wiley Periodicals, Inc. 
Table I.

Radiofrequency Ablation Catheters

\begin{tabular}{|c|c|c|c|c|}
\hline Catheter & Electrodes & RF Delivery & Advantages & Disadvantages \\
\hline $\begin{array}{l}\text { Standard } \\
\text { 4-mm-tip }\end{array}$ & & $\begin{array}{l}\text { RF energy } \\
\text { delivery }\end{array}$ & $\begin{array}{l}\text { Predictable lesion size } \\
\text { Good signal resolution }\end{array}$ & $\begin{array}{l}\text { Limited power delivery } \\
\text { Smaller lesion volume } \\
\text { and depth }\end{array}$ \\
\hline $\begin{array}{l}\text { Large 10- } \\
\text { mm-tip }\end{array}$ & & $\begin{array}{l}\text { Passive } \\
\text { cooling due to } \\
\text { large surface } \\
\text { area enables } \\
\text { more power } \\
\text { delivery }\end{array}$ & $\begin{array}{l}\text { Larger lesion volume } \\
\text { and depth }\end{array}$ & $\begin{array}{l}\text { Reduced signal } \\
\text { resolution } \\
\text { Thrombus and char } \\
\text { formation } \\
\text { Steam pop }\end{array}$ \\
\hline $\begin{array}{l}\text { Open- } \\
\text { irrigated } \\
3.5-\mathrm{mm}- \\
\text { tip }\end{array}$ & 8 & $\begin{array}{l}\text { External } \\
\text { irrigation } \\
\text { cools } \\
\text { electrode and } \\
\text { tissue } \\
\text { interface, } \\
\text { allows greater } \\
\text { power } \\
\text { delivery }\end{array}$ & $\begin{array}{l}\text { Increased lesion depth } \\
\text { and volume } \\
\text { Good signal resolution }\end{array}$ & $\begin{array}{l}\text { Intravascular fluid } \\
\text { overload } \\
\text { Risk of steam pops }\end{array}$ \\
\hline $\begin{array}{l}\text { Closed- } \\
\text { irrigated } \\
\text { 4-mm-tip }\end{array}$ & & $\begin{array}{l}\text { Internal } \\
\text { irrigation } \\
\text { cools } \\
\text { electrode, } \\
\text { allows greater } \\
\text { power } \\
\text { delivery }\end{array}$ & $\begin{array}{l}\text { Increased lesion depth } \\
\text { and volume } \\
\text { Good signal resolution }\end{array}$ & $\begin{array}{l}\text { Risk of thrombus } \\
\text { formation } \\
\text { Risk for steam pops }\end{array}$ \\
\hline
\end{tabular}

catheters can also create large and transmural lesions with an efficacy similar to open-loop irrigated-tip catheters, ${ }^{7}$ the probability of char and thrombus formation with large-tip catheters have limited their use in the arterial system. ${ }^{8}$ Large-tipcatheters, however, appear to be highly effective and efficient in ablation of atrial flutter in the right atrial venous system. ${ }^{9}$

There are no randomized studies that compared clinical outcomes of RF catheter ablation of AF using an open- versus closed-loop irrigatedtip catheter. However, there have been a few experimental studies. ${ }^{8,10,11}$ With an open-loop irrigated-tip catheter, the tip electrode is cooled by infusing saline at variable flow rates through a shower-head design. Although large lesions can readily be created with a limited risk of thrombus formation at the tip electrode, there remains two major areas of concern with this system: (1) "steam pops" due to excessive myocardial heating, ${ }^{10}$ and (2) potential risk of fluid overload due to intravascular volume expansion. Steam pops and myocardial overheating can usually be avoided by maintaining lower tip catheter temperatures $\left(<40^{\circ} \mathrm{C}\right),{ }^{11,12}$ by limiting the maximum power and carefully monitoring changes in impedance. However, it should be noted that these measures are not always predictive of significant rises in intramural temperature with subsequent steam pops. The average volume of saline infused during a typical ablation procedure for AF can reach $3 \mathrm{~L} .{ }^{13}$ In patients with heart failure, cardiomyopathy, or renal dysfunction who may not be able to tolerate even relatively modest increases in intravascular volume, this often necessitates close monitoring of intravascular filling pressures and diuresis during and after the procedure.

On the other hand, with a closed-irrigation system there is no need for fluid infusion. However, the tip-electrode still can be cooled and more power can be delivered. In this system, an internal circuit actively cools the catheter electrode tip without any intravascular infusion. In a prior experimental study, higher risk of thrombus formation and steam pops were observed with a closed-irrigated than an 
open-irrigated system. ${ }^{10}$ In an ex vivo model, the two irrigated systems were compared during a power-controlled ablation mode at 20 and $30 \mathrm{~W}$. Although both systems created similar tissue temperatures and lesion depth, the closed irrigation system resulted in greater thrombus formation (particularly with $30 \mathrm{~W}$ ) due to a higher electrodetissue interface temperature. Steam pops were also more common with the closed loop system at both power settings. A follow-up study suggested that altering the ablation settings can mitigate these risks. Ablation in a temperature-controlled $\left(42^{\circ} \mathrm{C}, 40 \mathrm{~W}\right)$ or impedance-monitored (with a target $10 \Omega$ decrease) strategy was associated with a lower risk of thrombus or steam pop formation compared to a fixed power setting (20 or $30 \mathrm{~W}){ }^{11}$

\section{References}

1. Golden K, Mounsey JP, Chung E, Roomiani P, Morse MA, Patel A, Gehi A. Atrial fibrillation ablation using a closed irrigation radiofrequency ablation catheter. Pacing Clin Electrophysiol 2012; 35:506-513..

2. Cappato R, Calkins H, Chen SA, Davies W, Iesaka Y, Kalman J, Kim YH, et al. Updated worldwide survey on the methods, efficacy, and safety of catheter ablation for human atrial fibrillation. Circ Arrhythm Electrophysiol 2010; 3:32-38.

3. Nakagawa H, Yamanashi WS, Pitha JV, Arruda M, Wang X, Ohtomo K, Beckman KJ, et al. Comparison of in vivo tissue temperature profile and lesion geometry for radiofrequency ablation with a saline-irrigated electrode versus temperature control in a canine thigh muscle preparation. Circulation 1995; 91:22642273.

4. Demazumder D, Mirotznik MS, Schwartzman D. Biophysics of radiofrequency ablation using an irrigated electrode. J Interv Card Electrophysiol 2001; 5:377-389.

5. Thomas SP, Aggarwal G, Boyd AC, Jin Y, Ross DL. A comparison of open irrigated and non-irrigated tip catheter ablation for pulmonary vein isolation. Europace 2004; 6:330-335.

6. Chang SL, Tai CT, Lin YJ, Lo LW, Tuan TC, Udyavar AR, Hu YF, et al. Comparison of cooled-tip versus 4-mm-tip catheter in the efficacy of acute ablative tissue injury during circumferential pulmonary vein isolation. J Cardiovasc Electrophysiol 2009; 20: 1113-1118.

7. Dixit S, Gerstenfeld EP, Callans DJ, Cooper JM, Lin D, Russo AM, Verdino RJ, et al. Comparison of cool tip versus 8-mm tip catheter in achieving electrical isolation of pulmonary veins for long-term
Whereas the temperature control mode resulted in a smaller lesion size, the impedance-controlled mode maintained similar lesion size as compared to the fixed power mode with an improvement in safety profile. Therefore, operation of the closed irrigation system with a temperature-controlled (as used in the study by Golden et al.) or impedance-monitored mode should offer a safer alternative to a strictly power-controlled mode.

Although this study by Golden et al. reports comparable outcomes, an accurate assessment of comparative efficacy, efficiency, and safety of RF catheter ablation of AF using an open- versus closed-irrigation catheter system remains to be determined in a randomized clinical trial with rigorous assessment of clinical outcomes.

control of atrial fibrillation: A prospective randomized pilot study. J Cardiovasc Electrophysiol 2006; 17:1074-1079.

8. Everett TH, Lee KW, Wilson EE, Guerra JM, Varosy PD, Olgin JE. Safety profiles and lesion size of different radiofrequency ablation technologies: A comparison of large tip, open and closed irrigation catheters. J Cardiovasc Electrophysiol 2009; 20:325-335.

9. Ilg KJ, Kühne M, Crawford T, Chugh A, Jongnarangsin K, Good E, Pelosi F, et al. Randomized comparison of cavotricuspid isthmus ablation for atrial flutter using an open irrigation-tip versus a largetip radiofrequency ablation catheter. J Cardiovasc Electrophysiol 2011; 22:1007-1012.

10. Yokoyama K, Nakagawa H, Wittkampf FH, Pitha JV, Lazzara R, Jackman WM. Comparison of electrode cooling between internal and open irrigation in radiofrequency ablation lesion depth and incidence of thrombus and steam pop. Circulation 2006; 113:11-19.

11. Thiagalingam A, D’Avila A, McPherson C, Malchano Z, Ruskin J, Reddy VY. Impedance and temperature monitoring improve the safety of closed-loop irrigated-tip radiofrequency ablation. J Cardiovasc Electrophysiol 2007; 18:318-325.

12. Cooper JM, Sapp JL, Tedrow U, Pellegrini CP, Robinson D, Epstein LM, Stevenson WG. Ablation with an internally irrigated radiofrequency catheter: Learning how to avoid steam pops. Heart Rhythm 2004; 1:329-333.

13. Nölker G, Gutleben KJ, Ritscher G, Rittger H, Asbach S, Heintze J, Muntean B, et al. Left atrial lesion formation and volume overload by open irrigation ablation technology during pulmonary vein antrum isolation: Acute effects on cardiac hemodynamics. J Interv Card Electrophysiol 2011; 31:125-130. 